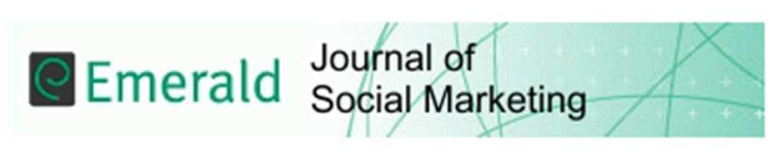

\title{
FACTORS POTENTIALLY AFFECTING THE SUCCESSFUL PROMOTION OF ELECTRIC VEHICLES
}

\begin{tabular}{|r|l|}
\hline Journal: & Journal of Social Marketing \\
\hline Manuscript ID & JSOCM-08-2015-0059.R2 \\
\hline Manuscript Type: & Empirical Paper \\
\hline Keywords: & $\begin{array}{l}\text { Environmental sustainability, Message framing, Message Style, Marketing, } \\
\text { Consumer attitudes }\end{array}$ \\
\hline \multicolumn{2}{|c}{} \\
\hline
\end{tabular}

SCHOLARONE ${ }^{\text {"x }}$

Manuscripts 


\title{
FACTORS POTENTIALLY AFFECTING THE SUCCESSFUL PROMOTION OF ELECTRIC VEHICLES
}

\begin{abstract}
Purpose

The purpose of the study was to identify whether the promotional materials used by government bodies and private producers to stimulate the mass market for electric vehicles (EVs) embodied themes deemed attractive by a sample of motorists in Greater London.

Design, methodology, approach

The EV websites and advertisements of EV manufacturers and the EV websites of relevant public bodies were subjected to semantic network and categorical content analyses. Outcomes were inputted to a conjoint analysis, the results of which were clustered into customer segments using the NORMCLUS generalised market segmentation procedure.
\end{abstract}

\section{Findings}

Substantial disparities between, on one hand, the EV characteristics emphasised in manufacturers' and public bodies' EV promotional materials and, on the other, potential EV buyers' views regarding the key qualities of EVs became evident.

Research limitations

The sample size of motorists was limited and the research was completed in a single country.

Practical implications

Social marketing campaigns initiated by government and private bodies concerning EVs need to incorporate specific themes reflecting the preferences of various segments of motorists.

\section{Social implications}

A 'one size fits all' approach is unlikely to be appropriate for the mass marketing of EVs. 
Originality / Value

This was the first study to explore the appeal to potential EV purchasers of the value of the contents of EV marketing messages employed by government bodies and vehicle manufacturers.

Key words: environment, electric cars, market segmentation, promotional message strategies, marketing communications.

\section{Introduction}

This paper examines how marketing can help foster environmentally sustainable behaviour (a field embraced by social marketers for many years - see McKenzie-Mohr, 2011; Andreasen, 2006; Beall et al., 2012; Wood, 2012) in an important area, namely the mass marketization of zero tailpipe-emission electric cars. Specifically it explores the appeal to potential EV purchasers of the contents of the EV marketing messages employed by vehicle producers and government bodies. McKenzie-Mohr (2011) observed how social marketing that simply provides information is not usually sufficient to cause behaviour change with respect to environmental sustainability. The right information has to be provided and this requires the discovery of barriers to the adoption of new behaviours. Henley et al. (2011) further noted how 'the identification of the right themes is crucial in order to reach the desired target audience to create attitudinal and behavioural change' and had become a central tenet of social marketing (p.697). Commercial marketing techniques such as market segmentation designed to position a market offering; the determination of product characteristics that appeal to target segments, and 'customer orientated' approaches in general can greatly facilitate social marketing campaigns (Andreasen, 2006; Donovan, 2011; Smith, 2011). The International Social Marketing Association Consensus Definition of social marketing acknowledged how conventional marketing techniques could assist in the delivery of 'efficient and effective segmented social change programmes' ISMA, 2014 p.1).

Public bodies and producers need to know the specific combinations of characteristics of EVs that motorists would regard as important were they to consider buying an electric car. This might involve the analysis of degrees of congruence between self-concept and product image (see Heath and Scott, 1998), the symbolic aspects of consumption (e.g., Heffner et al., 2007), possible relations between rational economic and aesthetic perceptions (see Sheller, 2004), and choice behaviour (Train and Winston, 2007). The present investigation examined such issues in the context of electric vehicles. It compared the features of EVs emphasised in the EV promotional messages used by manufacturers and government bodies with opinions expressed by a sample of 645 drivers of combustible fuel vehicles (none of whom had ever experienced an EV) in Greater London. 


\subsection{European Union and UK government support for the marketization of EVs}

European Union regulations to limit average emissions from new cars (approved in April 2010 and introduced in 2012) set a target of a 40\% reduction in average EU tailpipe emissions for the year 2020 based on 2009 levels. The UK Climate Change Act of 2008 had already committed the government to cut greenhouse gas emissions by $80 \%$ by the year 2050 , including an $80 \%$ reduction in transport emissions (Houses of Parliament, 2010). This would require the large scale adoption of electric vehicles, implying the need for the extensive development of the market for EVs by the year 2020 (Houses of Parliament, 2010). Internationally, the need to increase the number of EVs on the roads is a matter of substantial concern since, although one million EVs had been sold worldwide by mid-2015, this represented less than $0.1 \%$ of the 1.2 billion vehicles currently in use (Cobb, 2015). Only 310,000 EVs were registered in all of Western Europe between 2010 and 2015, mainly in Norway and the Netherlands.

In September 2013 the UK government reaffirmed its support of the early market for EVs (and for hybrids) via a $£ 400$ million two year programme designed to 'secure the maximum possible benefits to the economy from the mass-market adoption of zero and ultra-low emission cars' (OLEV, 2013 p.11). The government's objective was that 50\% of all cars and vans on Britain's roads should be zero or ultra-low emission by 2050 (Gov.UK, 2013). Hence the government established a specific Department to oversee low emission vehicle initiatives; part-funded research and development in the EV domain (including the offer of a $£ 10$ million prize to encourage the development of a non-rechargeable long distance car battery); and paid certain local government authorities up to $50 \%$ of the cost of installing recharging posts. Additionally the government provided a financial subsidy of (currently) up to $£ 5000$ against the purchase price of an ultra-low emission vehicle. These measures parallel those taken by the USA and several western European countries (for details see Houses of Parliament, 2010). Belgium, Canada, France, Japan, the Netherlands, Norway and in particular Sweden have offered cash incentives and tax relief to individuals buying EVs. In 2014 the UK government announced a grant of $£ 2.5$ million to a group of five leading EV manufacturers (BMW, Nissan, Renault, Toyota and Vauxhall) to help them execute a marketing campaign to educate the public about EVs and induce people to enter EV car showrooms (Hinks, 2014). The government also announced a further $£ 9$ million investment in motorway rapid charge points. Many other countries provide state support to EV producers (see Howell et al., 2014). The Chinese government for instance gives subsidies to EV manufacturers on the basis of its desire to develop China's EV industry and to reduce oil imports.

A key aim of the UK government's programme was the implementation of a national campaign to raise public awareness of the benefits of zero and ultra-low emission vehicles and to promote them 
to mainstream markets. This resulted from the government's recognition that 'as yet most people have little if any knowledge of these new vehicles' and that 'insufficient or inaccurate information can put off potential buyers' (OLEV, 2013 p.10). A number of studies reviewed by Burgess et al. (2013) confirmed the government's view, indicating that UK consumers are generally ignorant of how EVs work and of the EV driving experience. This was because usually potential buyers have no experience of electric vehicles and, although large numbers of people admire EVs, few actually purchase them. Consumer studies in Belgium (Heyvaert et al., 2015), Germany (Bauer et al., 2014) and Romania (see Racicovschi et al., 2007) have come to similar conclusions. At present EVs are expensive compared to other types of vehicle (although prices will fall as mass production occurs and as new competitors enter the market (cf. Urban et al. 1996)) and, in the words of Garling and Thogersen (2001), EVs 'hardly sell themselves to potential customers' (p.56), meaning that skilful governmental marketing and communications strategies were needed to secure mass market acceptance of the product.

\subsection{Vehicle manufacturers and the marketing of EVs}

The 2012 EU regulations provided motor manufacturers with financial incentives to develop new EV models. Producers were allocated targets for the limitation of average emissions from the vehicles they manufacture, with heavy fines for non-compliance. In particular, a zero or ultra-low emission vehicle counts as more than one car when a producer calculates its emissions average. Consequently, several major manufacturers launched new EVs within Europe. EVs are however 'high production cost, engineering intensive products that have to be batch (rather than mass) produced (Pilkington and Dyerson, 2006 p.80). Hence motor manufacturers have devised and implemented their own extensive EV marketing campaigns (as discussed in a later section) in attempts to stimulate sales and recover these initial investments.

\section{Factors potentially influencing vehicle purchasing decisions}

\subsection{General factors}

Studies of the considerations that affect private purchasers' choices of conventional motor vehicles (e.g., Lave and Train, 1979; Manski and Sherman, 1980; Choo and Mokhtarian, 2004; Rijnsoever et al., 2009; Prieto and Caemmerer, 2013) have identified a number of influential factors. One set of variables involves the characteristics of the vehicle; notably purchase price, fuel economy, size (including seating and luggage capacity), performance, running costs, appearance, image, comfort and reliability. Ferguson et al.'s (2003) content analysis of a sample of 850 worldwide car advertisements appearing between 1983 and 1998 found that performance (exemplified by speed, power and manoeuvrability) was the primary theme in nearly a fifth of all the advertisements in the 
sample. 'Economy' also figured in many of the advertisements. Another set of factors relates to the nature of the buyer: family size and composition, annual mileage, income, education level, residential location, age, gender, and number of drivers in the household. A further consideration is the number of cars owned by a household.

\subsection{Considerations specifically related to EVs}

Investigations expressly concerned with EVs (e.g., Eggers and Eggers, 2011; Ozaki and Sevastyanova, 2011; Hutchins et al., 2013) have focused on their benefits and problems. Alleged benefits include a quiet, smooth and gearless driving experience; good handling and fast acceleration; a government subsidy on purchase price and, of course, saving money on petrol. Hutchins et al's (2013) survey of 192 British private and 329 commercial EV users reported that over $85 \%$ of both groups deemed the government price subsidy to be an important consideration in their buying decision, although the majority of non-EV owners were unaware of the government grant. So far as fuel economy is concerned, a US survey of 2302 drivers in 21 large urban areas found that whilst 'enhanced fuel economy' was seen as the primary advantage of an electric car, it failed to exert a strong influence on purchase intention. The latter was shaped mainly by the extents of consumers' perceptions of the disadvantages of EVs (Carley et al., 2013 p.39). Drawbacks have been reported to extend to limited range, high purchase price, battery recharge durations, battery replacement costs (about $£ 4000$ after approximately 60,000 miles), battery life that decreases with low outside temperatures, and the limited availability of charging stations. Issues connected with charging have been found to be regarded as especially problematic by UK drivers. In Australia, McCowan (2013) reported that EV sales had been significantly held back by the lack of charging stations. Most private EV owners charge at home, which requires off-street parking. However one third of all UK households have to park their vehicles on the street (around $40 \%$ in central urban areas). Commercial providers of plug-in points have different charging and payment schemes and restrict access to their own set of subscribers. Sierzchula et al. (2014) examined possible connections between financial incentives and EV market share in 30 countries, finding a significant relationship but also that the size of a country's charging infrastructure exerted by far the strongest influence.

\subsubsection{Role of environmental concern}

Evidence concerning the impact on EV purchase decisions of a person's concern for the environment is limited, though it seems that buying an EV gives individuals the opportunity both to express their environmental responsibility and to demonstrate this to their valued peers (Ozaki and Sevastyanova, 2011; Sexton and Sexton, 2014). Rijnsoever et al's (2009) study of the private car buying process identified a significant gap between customer attitude towards the environment and 
actual behaviour when choosing a car. People who exhibited environmentally friendly behaviour in several other spheres and who in addition held positive environmental attitudes were more likely than others to translate their attitudes into actual purchases of EVs. In the UK a government survey of 3600 people found that whilst $60 \%$ of the participants felt they knew little about environmental issues, most individuals were 'aware and concerned about damage to the environment and want to do something about it' and believed that 'being green is now the socially acceptable norm' (Eccleston, 2007 p.1). It is known moreover that strong concern for the environment can exert powerful effects on the consumption behaviour of people high in the tendency (Van Liere and Dunlap, 1980; Sexton and Sexton, 2014).

A person's choice of car can communicate the individual's interests, values, beliefs and status (Steg et al., 2001) especially, according to a number of studies, in relation to electric vehicles (see Eggers and Eggers, 2011; Sexton and Sexton, 2014). Thus some individuals might obtain an EV to express their self-identity, to help create a certain self-image, and to be seen as environmentally friendly (see Ozaki and Sevastyanova, 2011 for details of relevant literature supporting these propositions). Image related factors of this nature 'can override more rational utility-based calculations' (Burgess et al., 2013 p.35).

\section{Content analysis of manufacturers' promotional materials}

To establish the views of EV manufacturers regarding the characteristics of EVs they deemed most worthy of mention in promotional materials, a semantic network analysis (SNA - see Krippendorff, 2012) of manufacturers' promotional materials was undertaken. This examined word frequency, word co-occurrence and word proximity in the texts of the materials with the aim of uncovering the major themes embedded within messages. At the time the research was completed, 14 purely electric vehicle models produced by 10 manufacturers were available in the UK. For companies that supplied more than one EV model it emerged that the contents of the materials promoting each of the firm's models were very similar, so only the materials relating to one of the models were examined. For each of the 10 models considered (one per manufacturer), the webpages and the current print advertisement for the model were analysed. Prior and during the period when the study was undertaken, television advertisements for the EV models were rare and on the very few occasions they appeared their contents followed closely the messages embodied in print advertisements.

The SNA was undertaken using Catpac software (Woelfel, 1998), which analyses relationships among frequently occurring words within textual data as a precursor to identifying the main concepts associated with specific collections of words. The webpages of each of the ten EV models considered typically contained an on-line brochure (or equivalent) for the model in question 
with 800 to 1100 words of text. Print advertisements usually had 350 to 400 words. Relevant words appearing most frequently in each piece of material were analysed. 'Relevant' words comprise those words that convey valuable content or information concerning the topic of the investigation (Woelfel, 1998). Following the exclusion of mundane words with no particular relevance to the study, the most frequently used words (or words that were directly equivalent) appearing in the 20 pieces of promotional material were: pleasure (18 mentions in total, the word occurring in seven of the ten websites and six of the print advertisements), fuel (saving of) (18 mentions in total, seven in websites, six in print advertisements), price $(16 ; 6 ; 5)$; performance $(11 ; 5 ; 4)$, technology (advanced) $(8 ; 4 ; 4)$, environment $(7 ; 3 ; 3)$, and energy $(6 ; 3 ; 3)$. The combined texts of all the producers' materials were entered into the Catpac sub-routine Oresme, which was used to perform a non-hierarchical clustering of the co-occurrences of the above words within a (Catpac default) seven-word moving window. Oresme establishes which words are activated most frequently within the moving window when a particular key word is specified (see Woelfel and Stoyanoff, 1994). There was no evidence of excessive concentration of particular words within specific websites or print advertisements, i.e., it was not the case that certain words or cooccurrences were found repeatedly within just a couple of pieces of material. The exercise identified the three distinct clusters of words (each representing an underlying conceptual theme named by the authors) shown in Figure 1.

Figure 1 indicates that three semantic concepts dominated the core messages presented in manufacturers' promotional materials, i.e., that EVs offer a great driving experience, are economical, and help preserve the environment. 'Great driving experience' derived from the confluence of words to do with EV driving pleasure, excellent performance and the application of advanced technology. The concept 'economical' involved words describing (i) the absence of any need to purchase fuel, and (ii) falling purchase prices and the availability of the government's price subsidy. 'Preserves the environment' was predicated on words connected with environmental cleanliness and with saving the nation's energy resources.

\subsection{Categorical content analysis}

Next a categorical content analysis (CCA) was completed to identify and count the themes emerging from the SNA that were contained in each piece of the manufacturers' promotional materials. The CCA was undertaken by three individuals working independently. Inter-rater reliability was assessed using Fliess' kappa, the value of which $(k=.8)$ indicated good agreement among the raters (Landis and Koch, 1977). Percentage agreement scores exceeded $80 \%$ in all cases and the covariations in the scores were high (Pearson's r $r .88$ ). The result of the exercise showed that the theme 'Great driving experience' appeared in some form or other in all of the ten websites and all of the print advertisements. The theme 'economical' was prominent in eight of the 
websites and seven of the print advertisements; the theme 'preserves the environment' occurred in seven websites and six print advertisements.

\section{Analysis of the websites of public bodies}

The exercise was repeated for EV related materials (appearing predominantly on websites rather than in printed form) created by public bodies. As the study was completed in London it was appropriate to examine the websites of public bodies that might be seen by potential buyers of EVs residing in London. At the time the investigation was undertaken, 13 London Boroughs had policies and webpages promoting EVs. Additionally the websites of the Greater London Authority and Source London (an organisation managed by Transport for London on behalf of the Office of the Mayor of London) contained promotional information on electric vehicles. Each of these websites had pages supporting EVs with between 800 and 1000 words of text. A Catpac analysis of these materials revealed that the following relevant words appeared most frequently in the 15 website sections dealing with EVs: battery (including discussions of battery warranties and battery toxicity and disposal facilities) (37 mentions in total, the word occurring in all 15 websites), range $(26 ; 13)$, charging $(24 ; 15)$, fuel (saving) $(8 ; 8)$, energy $(7 ; 7)$, price (subsidy) $(6 ; 6)$, emissions $(5 ; 5)$, $\mathrm{CO}_{2}(4 ; 4)$.

Figure 2 shows the four cluster solution generated by the application of the Catpac Oresme procedure to the co-occurrence matrix of relevant words within the combined text of the 15 sets of webpages. (The words in parentheses in Figures 1 and 2 indicate the contexts in which the main words were employed in the texts.) There was no evidence of co-occurrences of certain words appearing in excessive quantity in any of the public bodies' websites. A categorical content analysis of the websites of 15 public bodies revealed that the theme 'range anxiety' occurred in all 15 websites; the theme 'battery issues' appeared in 13 of the websites; 'economical' in nine, and 'preserve the environment' in six $(k=.82 ; r=.84)$.

\section{Comparison of the promotional materials of manufacturers and public bodies}

It is clear from Figures 1 and 2 that substantial disparities existed in the characteristics of EVs that were promoted by motor manufacturers compared to public bodies, and neither the manufacturers nor the public bodies included in their materials issues (suggested by academic literature in the car marketing field) concerning a driver's self-image, particularly the ability to use an EV purchase to display an individual's environmental concern. Producers placed heavy emphasis on the pleasurable experience of driving an EV, the performance of new EV models, low running costs, and protection of the environment. An Oresme analysis of key word co-occurrences revealed that messages to do with national energy conservation, the environment, the use of advanced 
technology in EVs, and performance (speed, acceleration, etc.) tended to appear at the end rather than at the beginning of pieces of promotional material.

Materials devised by public bodies focused overwhelmingly on the provision of factual information about charge point availability, battery life, charging durations, and the distances an EV could travel. These materials appear to have been designed mainly to reduce range anxiety. Like manufacturers, public bodies included in their copy the message that EV owners can save money while improving the environment. An Oresme analysis indicated that words relating to energy, emission levels and fuel efficiency were likely to appear after words connected with charging and other battery issues.

\section{Conjoint analysis}

The outputs from the SNA were used as inputs to a conjoint analysis designed to determine the features of EVs most likely to attract members of the general public. This analysis sought to establish the perceptions of the major desirable characteristics (e.g., 'economical'; 'great driving experience') of EVs held by a sample of potential buyers of EVs living in Greater London. Each desirable characteristic has a number of elements. For instance, the characteristic 'great driving experience' could mean that an EV is a pleasure to drive, or that it provides excellent performance (e.g. fast acceleration), or that it uses the very latest motor vehicle technology. 'Economy' may be defined in terms of fuel savings, or the fact that an EV purchase attracts a substantial governmental subsidy.

Conjoint analysis allows the researcher to establish a person's views on the importance of various properties of an entity. Respondents are forced to reveal their rankings of preferred statements about the elements of the characteristics of the entity, and the relative strengths of their opinions are thus disclosed. The conjoint analysis was operationalised by presenting the participants with a list of alternative combinations of elements of the characteristics of EVs and telling them to rank each combination in order of how important a combination was to the respondent personally. Not all of the combinations offered to the participant contained all the features that a person might deem critically important, hence compelling the respondent to make trade-offs among the elements and to decide which were most and least critical for that person.

Analysis of an individual's ranking decision reveals the relative weights ('part worths') that the individual ascribes to each element. A part worth reflects (in conjoint analysis terminology) the 'importance' to a person of the element involved. Thereafter, average part worths can be computed for each element for the entire sample, and the profiles of groups expressing certain sets of rankings may be explored. 'Importance scores' for the overall characteristics (e.g., great driving 
experience) to which particular elements apply are calculated by dividing the part worth range for a particular characteristic by the sum of all part worth ranges.

\subsection{Choice of elements}

The conjoint design employed is shown in Table1 and was based on a synthesis of the themes listed in Figures 1 and 2, with an additional dimension (i.e. the opportunity that EVs provide for enabling individuals to demonstrate their concern for the environment) that did not emerge from the content analysis, but which figures prominently in the EV academic literature. Thus, the document summarised in Table 1 presented the respondent with choices involving three elements of the characteristic 'great driving experience' (i.e. pleasure to drive, good performance, use of the latest technology); two elements of the characteristic 'preserves the environment' (i.e. helps preserve the environment and 'gives buyers the opportunity to demonstrate their concern for the environment'); two elements of 'economical' (no need to purchase fuel and price subsidy); and three elements of a characteristic described as 'reassurance regarding range anxiety'. The last of these ('reassurance') subsumed concerns about 'battery issues' (see Figure 2) and involved three elements, i.e. longer battery life and cheaper battery replacement prices; longer distances between recharges; and greater availability of recharging points. Table1 did not offer separate elements for 'energy', 'emission' or ' $\mathrm{CO}_{2}$ ', these being subsumed into the general characteristic 'preserves the environment'. To check the face validity of the conjoint items, a single question was posed to a sample of 75 individuals who declared themselves to be motorists and who were approached at random in street locations in Central London. The question asked respondents what they thought were the main characteristics of (i.e., 'things that are most important about') electric cars compared to conventional cars. Collation of the replies did not reveal any major issues not covered in the preexisting conjoint questions.

\subsection{Conjoint procedure}

As there are dozens of possible combinations of the $(3 \times 3 \times 2 \times 2)$ elements covered by the analysis, it was necessary to reduce the number of combinations to the minimum necessary to be able to calculate part worths. The Orthoplan procedure of the SPSS 20 statistical software package was employed for this purpose, reducing the ranking requirement to just nine combinations. This meant that the ranking form given to the participants could be completed in a few minutes and was not unduly cognitively taxing. Nevertheless it was necessary to guard against any possibility of respondent fatigue affecting the outcomes. Hence the nine options were spread across three pages in a large typeface and were accompanied by a cartoon picture of an EV on each page. Alongside each option was a box within which, having read the nine options, the participants inserted their ranking ( 1 to 9 ) of the particular item. Each of the nine options listed in Table 1 contained a combination of four desirable elements of EVs, drawn from the total of ten elements 
mentioned above. However, each option had a different combination of elements and, because the combinations were different, the participant had to rank the combinations (from 1 to 9 ) according to which combinations contained most of the elements the person valued most highly. The conjoint procedure then 'disentangles' the respondent's preferences and ascribes the highest part worth to the element the individual deemed most critical, the second highest part worth to the element seen as second most critical, and so on. Part worths for each individual can then be averaged across the entire sample and then for specific groups. Table 2 shows the averaged part worths for each of the ten desirable elements of EVs recorded for the total sample and also for each of the three clusters within the aggregate sample.

Motorists without previous experience of EVs (owning or having driven) were asked to suppose that they were considering buying an $\mathrm{EV}$ and to rank in order various combinations of factors they would take into account when deciding whether to purchase this type of vehicle. People without experience of EVs represent the target market because of the extremely low levels of EV purchase. Fewer than 6000 non-hybrid EVs were sold in the UK in 2014, compared to sales of 2.4 million conventional vehicles (Nicholls, 2015). Internationally EV sales comprise less than $0.1 \%$ of the world's total vehicle stock (Cobb, 2015). Individuals seriously contemplating an EV purchase may have characteristics different to people with no experience of $E V s$, but such potential buyers are not the target of interest for policy makers. Rather it is the huge market of people who are unaware of EVs that has to be penetrated if EV sales are to rise.

The conjoint section was followed by questions (see Table 1) about a participant's personal characteristics (age, household structure, types of journeys undertaken, etc. (cf. Choo and Mokhtarian, 2004)) and by items measuring a respondent's concern for the environment (adapted from Carley et al., 2013), actual environmental behaviour (adapted from Ozaki and Sevastyanova, 2011), and the person's propensity to regard EV purchase as a means for overtly displaying an individual's desire to be an environmental 'trendsetter' (adapted from Ozaki and Sevastyanova [2011]). An ad hoc item queried the extent to which the respondents used their vehicles for leisure pursuits. Information was gathered by paid research assistants and postgraduate students in street locations in Greater London and in places of employment (subject to a business's management giving permission) in Central London. Eventually 645 completed questionnaires were obtained. The four items for the 'concern for the environment' construct were factor analysed, a unidimensional solution emerging (lambda $=3.4$, Cronbach's alpha $=.92$ ). Unidimensional factor solutions also arose for 'actual environmental behaviour' (lambda $=5.0$, alpha $=.90$ ) and for the belief that $E V$ purchase enabled people to display their concern for the environment (lambda $=3.4$, alpha $=.91)$. Hence each set of items was averaged to form a composite to reflect the relevant construct.

\subsection{Segmentation of the conjoint solution}


The outcomes from the conjoint analysis were segmented using the NORMCLUS generalised normative segmentation methodology for conjoint results suggested by DeSarbo and DeSarbo (2007). This creates segments wherein preference structures differ from each other and where customer characteristics are different and identifiable. NORMCLUS (see DeSarbo and Grisaffe, 1998) has advantages over alternative clustering methods in that individuals may belong to more than one segment and minimum segment sizes (by default ten per cent of the total sample) may be imposed. When applied to conjoint analysis outcomes (DeSarbo and DeSarbo, 2007), the procedure clusters into disparate groups individuals possessing similar opinion structures (as revealed by the part-worths arising from the conjoint analysis), thus avoiding any need to specify segments a priori according to customer characteristics (which themselves might not fall into logically differentiated categories). The characteristics of the members of each opinion set may then be specified post hoc.

\section{Results}

\subsection{Descriptive results}

The participants had an average age of 44.8 years ( $33 \%$ were under age 40 and $36 \%$ over age 50 ) and $49 \%$ were female. They had an average of 1.83 children living with them and $64 \%$ had offstreet parking. A fifth of the sample described their household income as 'higher' than most other people; $30 \%$ as lower. Average annual household mileage was 4300 miles (31\% less than 3000 miles; $30 \% 3000$ to 6000 ), with just $8 \%$ of the respondents stating that their car usage requirements involved all day use. Sixty-eight percent of the sample used their cars for short and long distance journeys; $25 \%$ for short distance journeys only. This latter situation differs from that prevailing in some other countries (notably in Scandanavia) where short journeys are the norm. The fact that so many of the sample members used their cars for long as well as short journeys underscores the need for the UK government to extend and improve the country's charging infrastructure (Hutchins et al., 2013; see also Ozaki and Swvastyanova, 2011; McCowan 2013). Only $17 \%$ of the sample was aware of the availability of the $£ 5000$ government grant. Similar outcomes have been observed in other studies and in other countries (e.g., Hutchins et al., 2013; Bauer et al., 2014; Heyvaert et al., 2015). Clearly manufacturers and public bodies need to advertise the $£ 5000$ grant more prominently in their promotional literature, e.g., via a joint campaign. Twenty-eight percent of the responses fell in the top two categories of the composite formed for the 'construct concern for the environment' (see Table 1); $20 \%$ fell in the top two categories of the construct 'actual environmental behaviour' and $18 \%$ in the top two categories of 'belief that EV purchase enables people to display their concern for the environment'. It is evident therefore that promotional materials should emphasise several EV features additional to their contributions to environmental improvement. 


\subsection{Outcomes to the conjoint analysis}

Table 2 gives the conjoint solution for the total sample plus the solutions for each of the three clusters identified by the NORMCLUS procedure. Cluster membership was allowed to overlap but no cluster was permitted to contain less than ten per cent of the total sample. The three-segment solution exhibited substantially better goodness-of-fit ( $p h i=0.7$ ) than the one or two cluster outcomes (phi=0.2 and 0.51 respectively) but improved only slightly (phi=0.71) for four clusters. The within-segment R-square values (weighted by the proportion of the sample in each segment see DeSarbo and Grisaffe, 1998) substantially exceed the magnitude of the total sample unsegmented R-square, indicating successful segmentation with respect to the conjoint parameters. Figure 3 gives the overall characteristic importance scores for the aggregate solution; Figure 4 shows the characteristic importance scores for the three segments.

Among the sample as a whole the characteristic 'great driving experience' was deemed the most important consideration likely to affect a decision to purchase an electric vehicle (accounting for $38 \%$ of the total of the importance values). 'Reassurance about range anxiety' came second (29\%), followed by 'preserves the environment' (20\%) and, some considerable way behind, 'economical' $(13 \%)$. For the majority of people in the sample, therefore, messages emphasising the pleasure of driving, the high performance and the fact that charging facilities are becoming more widespread are the most likely to be effective. The part worth values pertaining to each of the characteristics shown in Table 2 indicate the averaged sample members' preferences for particular elements. A positive part worth value means a preference for the element in question and the higher the value the greater the preference. Inspection of the contributions of the elements of 'great driving experience' reveals that 'pleasure to drive' had a positive part worth suggesting that among the sample as a whole this element was regarded as the most critical aspect of 'great driving experience'. Positive part worths for elements of the other characteristics were 'recharge points will soon be widely available'; 'providing the opportunity to demonstrate one's concern for the environment'; and not needing to buy fuel.

The conjoint solutions for the three clusters shown in Table 2 display different patterns vis-à-vis the EV characteristics deemed most important on average by a cluster's members. Table 3 presents the profiles of the members of each of the clusters. Only the variables for which substantial differences in mean values or percentages were discernible are shown in the table. No significant disparities $(p<.05)$ between clusters occurred in relation to respondent age, education level, household income, car usage requirements (short versus long distance journeys), or whether a respondent had off-street parking. It seems therefore that there would be little point in differentiating promotional messages in terms of these particular criteria. This result reflects perhaps a greater acceptance of the desirability of environment-improving products and activities 
among the general public. Thus for instance the older people in the sample were just as likely to have environmentalist inclinations as younger individuals. The younger members of the sample were not more cost-conscious than others. Likewise the less well-educated respondents were as likely to have environmental concern as the better-educated, again possibly indicating a growing acceptance of 'greenism' among the general public (Eccleston, 2007 p.1). Also the sample members' perceptions of EV characteristics did not vary with respect to household income: the financially better-off seemingly recognised the cost advantages of EVs to much the same extent as the financially poor.

Relating Table 3 to the segmented conjoint solutions given in Table 2 it can be seen that the largest cluster (C1), which contained 314 respondents (including 29 individuals who also appeared in cluster 2), might reasonably be described as a cluster of 'family first' people. Members of this cluster valued the great driving experience (particularly 'pleasure to drive') offered by EVs and their economical nature (notably falling prices); but were less concerned with range anxiety (though distance between recharges was seen as important), and exhibited little interest in preserving the environment. (The last factor accounted for just 3.6\% of total importance.) The significant distinguishing features of 'the family first' cluster were its inclusion of a majority (59\%) of females, of people with a higher than average number of children living with them, and individuals who used their cars for leisure purposes to greater extents than the remainder of the sample. Only $13 \%$ of cluster one knew about the $£ 5000$ government grant. Clearly, family first individuals represent a critical target market.

Cluster two ( $\mathrm{N}=217$, including 29 individuals located in $\mathrm{C} 1)$ may be characterised as a cluster of 'cost cutters'. People in C2 regarded the factor 'economical' as the most important characteristic of EVs (49\% of total importance), and were also concerned with 'reassurance regarding range anxiety' (37\%). Cluster two members were relatively unconcerned about 'great driving experience' (nine per cent) or with preserving the environment (five per cent). As regards specific elements of these factors, C2 members valued not having to buy fuel, longer battery life and falling battery replacement cost, increasing distances between recharge points, and a pleasurable driving experience. Individuals in $\mathrm{C} 2$ tended to be male, to have fewer children living with them, more cars in their household, and to record higher annual mileages. Cluster three comprised 114 'environmentalists' who reported 'preserves the environment' as their most important consideration ( $51 \%$ of the total). There were no overlaps between membership of C3 and C1 or C2. Cluster three members saw 'reassurance regarding range anxiety' as the next most important factor $(27 \%)$, yet were not particularly impressed by the prospect of a 'great driving experience' (15\%) or by the proposition that EVs are 'economical to drive' (six per cent). On average they owned fewer cars than the rest of the sample, drove substantially fewer miles, used their cars for fewer leisure 
journeys, were more likely to be aware of the government grant, and (predictably) were extremely concerned for the environment.

The lower levels of concern for the environment and actual environmentally-friendly behaviour exhibited by members of $\mathrm{C} 1$ and $\mathrm{C} 2$ suggest the need to stimulate interest in environmental issues among these individuals as a spur to encouraging them to find out more about EVs. Also the people in $\mathrm{C} 1$ and $\mathrm{C} 2$ had higher mileages than those in $\mathrm{C} 3$, indicating perhaps the usefulness of emphasising the fuel saving benefits of EVs to people with $\mathrm{C} 1$ and $\mathrm{C} 2$ characteristics.

The larger number of females in C1 is linked perhaps to family-related issues (considering that $\mathrm{C} 1$ members had higher than the average number of children and possibly therefore with the wider use of vehicles for family leisure purposes. People in cluster two had more cars per household and higher average mileages than the rest of the sample, suggesting the desirability of fuel economy and, because multiple car households might be relatively heavy users of vehicles, the need to address concerns with battery life in promotional messages. The finding that individuals in C3 had lower average mileages is in line with the idea that the environmentally concerned will not want to travel by car unnecessarily. Range anxiety is less likely to worry people with limited mileages. However fuel cost considerations may be less salient among such individuals. Members of $\mathrm{C} 1$ were on the average less aware of the availability of the $£ 5000$ government grant yet were attracted by the economical nature of EVs, thus presenting a promotional opportunity for communicating information about the grant to this group of people.

\section{Conclusion}

The study found that the promotional materials of EV manufacturers emphasised the excellent driving experience offered by EVs, their economy, use of the latest motoring technologies, and the benefits of EVs for environmental preservation. Provision of reassurances regarding range anxiety (distances between recharges, battery charging durations, etc.) did not figure prominently in producers' materials. The public bodies covered by the research applied a different approach to the promotion of EVs; placing great emphasis on improvements in battery technology and charge point availability and on increasingly longer distances between charges. These aspects of EVs appeared to dominate the thinking underlying the construction of public bodies' messages, although cost savings and environmental protection issues were also mentioned.

Comparing the above with the views of members of the public, on average the members of the total sample believed that 'a pleasurable driving experience' was the most important EV quality likely to induce them to purchase an electric car. The second most important consideration was their being reassured about range anxiety (the primary theme included in public bodies' materials). 
On average, environmental preservation and economic factors were deemed less important as potential influences on purchase decisions. Sharp differences occurred however among the results for the three clusters of respondents within the overall sample; indicating the need to target various sub-divisions of the market in disparate ways. The members of each of the three segments had specific average profiles and preference structures. In common with the average values for the total sample, 'family first' individuals regarded 'pleasurable driving experience' as the most important consideration and valued the proposition that EVs are economical. People in this group tended to express little interest in the connection between EVs and environmental preservation. 'Cost cutters', conversely, were relatively unconcerned about EV driving experience and were mainly influenced by 'economy' and reassurance about range anxiety. Again, members of this group on the average did not view preservation of the environment as a major consideration. Individuals in the third and smallest cluster saw environmental preservation as the major quality of EVs likely to affect a decision to buy an electric vehicle, followed by reassurance regarding range anxiety. 'Great driving experience' and economic factors were not seen as particularly important influences.

\subsection{Implications}

It appears that EV manufacturers could improve the appeal of their promotional materials through incorporating in them content themed around the provision of reassurance about range anxiety to potential customers. The emphasis on pleasurable driving, while largely ignoring range anxiety, is unsurprising perhaps given the tendency noted by Donovan (2011) of commercial marketers engaged with social marketing to apply commercial marketing tenets and ideologies that may not be appropriate when pursuing societal objectives. It is relevant to note in this connection how, according to the Consensus Definition of Social Marketing, the practice of social marketing should seek to 'integrate marketing concepts with other approaches to influence behaviours... for the social good' (ISMA, 2014 p.1). Improvements in producers' message content might be achieved by conveying messages that emphasise the increasing availability of recharge points (with links to maps of recharge station locations and information on mobile 'phone 'apps' that provide rapid assistance with journey planning to ensure proximity to recharge points); the long life of modern batteries (backed up by a manufacturer's offer of [say] a five year or high mileage guarantee and perhaps the offer of a sizeable discount on battery replacement cost); and the fact that there is no need whatsoever to recharge during the vast majority of city journeys. For their part, public bodies could beneficially adapt their materials by including information on the great driving experience that EVs can provide,.

The results strongly suggest however that a 'one size fits all' approach may not be appropriate for the mass marketing of EVs. Differentiation of message content by specific EV suppliers to suit 
various segments might be undertaken according to the particular EV model produced by a manufacturer and its likely appeal to relevant groups. Further differentiation might be useful according to potential customers' levels of awareness of EVs (minimal or well-developed), given that a high degree of awareness might cause a consumer to occupy a different position within the EV buying decision process than that applicable to someone who is totally ignorant of EVs. The latter person may require a communications package containing considerably more than straightforward information about electric cars. Appropriate messages delivered to individuals at the very beginning of the decision cycle can stimulate need recognition (social and environmental as well as functional) and trigger information search regarding EVs.

\section{Acknowledgements}

This investigation was sponsored by the UK Department of Communities and Local Government and financed by the European Commission as a component of the European Union Regional Development Fund Interreg IV project: North Sea Electric Mobility Network, grant number CCI 2007CB163PO055; NSR 35-2-6-11.

The research assistance of Natali Dimitrova and Manisha Pal is gratefully acknowledged.

\section{References}

Andreasen, A. (2006), Social Marketing in the $21^{\text {st }}$ Century, Sage, New York.

Bauer, R., Menrod, K. and Decker, T. (2014), Alternative fuel vehicles: Preferences, attitudes and motives of German students in the field of mobility, International Journal of Electric and Hybrid Vehicles, 6 (4), 298-314.

Beall, T., Wayman, J., D’Agostino, H., Liang, A. and Perellis, C. (2012), Social marketing at a critical turning point, Journal of Social Marketing, 2 (2), 103-117.

Burgess, M., King, N., Harris, M. and Lewis, E. (2013), Electric drivers' reported interactions with the public: Driving stereotype change, Transportation Research, 17 Part F (1), 33-44.

Carley, S., Krause, R., Lane, B. and Graham, J. (2013), Intent to purchase a plug-in electric vehicle: A survey of early impressions in large US cites, Transportation Research, 18 Part D (1), 39-45.

Cobb, J. (2015), One million global plug-in sales milestone reached, Hybrid Cars, www.hybridcars.com/one-million-global-plug-in-sales-milestone-reached. Accessed on 11 October 2015.

Choo, S. and Mokhtarian, P. (2004), What type of vehicle do people drive? The role of attitude and lifestyle in influencing vehicle type choice, Transportation Research, 38 Part A (3), 201-222. 
DeSarbo, W. and DeSarbo, C. (2007), A generalised normative segmentation methodology employing conjoint analysis, in A. Gustafsson, A. Herrmann and F. Huber (Eds), Conjoint Measurement: Methods and Applications, Fourth Edition, Springer, Berlin, pp. 321-345..

Desarbo, W. and Grisaffee, (1998), Combinational optimisation approaches to constrained market segmentation: An application to industrial market segmentation, Marketing Letters, 9 (2), 115-134.

Donovan, R. (2011), Social marketing's mythunderstandings, Journal of Social Marketing, 1 (1), 816.

Eccleston, P. (2007), Public concerned on environment, survey says, The Telegraph, 2 November 2007, www.telegraph.co.uk/news/earth/eathnews/3312688/Public-concerned-on-environmentsurvey-says.html. Accessed on 12 October 2015.

Eggers, F. and Eggers, F. (2011), Where have all the flowers gone? Forecasting green trends in the automobile industry with a choice-based conjoint adoption model, Technological Forecasting and Social Change, 78 (1), 51-62.

Ferguson, S., Hardy, A. and Williams, A. (2003), Content analysis of television advertising for cars and minivans: 1983-1998, Accident Analysis and Prevention, 35 (6), 825-831.

Garling, A. and Thogersen, J. (2001), Marketing of electric vehicles, Business Strategy and Environment, 10 (1), 53-65.

Gov.UK (2013), Government Drives Forward Plug-in Revolution, London, Office for Low Emission Vehicles, www.gov.uk/news/government/government-drives-forward-plug-in-car-revolution. Accessed on 6 March 2014.

Heath, A. and Scott, D. (1998), The self-concept and image congruence hypothesis: An empirical evaluation in the motor vehicle market, European Journal of Marketing, 32 (11/12), 1110-1123.

Heffner, R., Kurani, K. and Turrentine, D. (2007), Symbolism in California's early market for hybrid electric vehicles, Transportation Research, 12 Part D (6), 396-413.

Henley, N., Raffin, S. and Caemmerer, B. (2011), The application of marketing principles to a social marketing campaign, Marketing Intelligence and Planning, 29 (7), 697-706.

Heyvaert, S., Coosemans, J., Van Mierlo, J. and Macharis, C. (2015), Electric vehicle attitudes and purchase intentions: A Flemish case study, International Journal of Electric and Hybrid Vehicles, 7 (1), 83-100.

Hinks, J. (2014), UK government extends lucrative electric car subsidies and launches new 2.5 scheme to improve uptake, IT Proportal, 31 January 2014, www.itproportal.com/2014/01/31/ukgovernment-extends-lucrative-electric-car-subsidies-and-launches-new-25m-scheme-improveuptake. Accessed on 10 September 2014 at

Houses of Parliament (2010), Electric Vehicles, Postnote 365, October 2010, Houses of Parliament, Parliamentary Office of Science and Technology, London.

Howell, S., Lee, H. and Heal, A. (2014), Leapfrogging or Stalling Out: Electric Vehicles in China, Harvard University, Cambridge MA.

Hutchins, R., Delmonte, E., Stannard, J., Evans, L. and Bussell, S. (2013), Assessing the Role of the Plug-in Car Grant and Plugged-in Places Scheme in Electric Vehicle Take-up, Transport Research Laboratory, London. 
ISMA (International Social Marketing Association) (2014), Social Marketing Definition, www.isocialmarketing.org/index. php?option=com content\&view=article\&id=84: social-marketingdefinition\&catid=28:front-page\#.Vhpq103jhjo. Accessed on 2 August 2015.

Krippendorff, K. (2012), Content Analysis: An Introduction to its Methodology, Sage, London.

Landis, J. and Koch, G. (1977), The measurement of observer agreement for categorical data, Biometrics, 33 (2), 159-174.

Lave, C. and Train, L. (1979), A disaggregate model of auto-type choice, Transportation Research, 13 Part A (1), 1-9.

Manski, C. and Sherman, L. (1980), An empirical analysis of household choice among motor vehicles, Transportation Research, 14 Part A (4), 349-366.

McCowan, D. (2013), The rise and fall of Better Place, Drive.com, www.drive.com.au/motornews/the-rise-and-fall-of-better-place-20130218-2emmn. Accessed on 11 October 2015.

McKenzie-Mohr, D. (2011), Fostering Sustainable Behaviour: An Introduction to Community Based Social Marketing, New Society Publishers, Exeter.

Nicholls, L. (2015), Green vehicle demand revs up as UK electric car sales quadruple, The Guardian, 8 January 2015, www.theguardian.com/environment/2015/jan/08/green-vehicledemand-revs-up-uk-electric -car-sales-quadruple. Accessed on 12 October 2015.

OLEV (Office for Low Emission Vehicles) (2013), Driving the Future Today: A Strategy for Ultra-low Emission Vehicles in the UK, Office for Low Emission Vehicles, London.

Ozaki, R. and Sevastyanova, K. (2011), Going hybrid: An analysis of consumer purchase motivations, Energy Policy, 39 (5), 2217-2227.

Pilkington, A. and Dyerson, R. (2006), Innovation in disruptive regulatory environments: A patent study of electric vehicle technology development, European Journal of Innovation Management, 9 (1), 79-91.

Prieto, M. and Caemmerer, B. (2013), An exploration of factors influencing car purchasing decisions, International Journal of Retail and Distribution Management, 41 (10), 738-764.

Racicovschi, V., Chefneux, M. and Danciu, G. (2007), Romanian concerns in the field of electric vehicles, International Journal of Electric and Hybrid Vehicles, 1 (1), 46-56.

Rijnsoever, F., Farla, J. and Dijst, M. (2009), Consumer car preferences and information search channels, Transportation Research, 14 Part D (3), 334-342.

Sexton, S. and Sexton, A. (2014), Conspicuous conservation: The Prius halo and willingness to pay for environmental bona fides, Journal of Environmental Economics and Management, 67 (3), 303-317.

Sheller, M. (2004), Automotive emotions: Feeling the car, Theory, Culture and Society, 21 (4/5), 221-242.

Sierzchula, W., Bakker, S., Maat, K. and Van Wee, B. (2014), The influence of financial incentives and other socio-economic factors on electric vehicle adoption, Energy Policy, 68 (2), 183-194.

Smith, B. (2011), Defining social marketing, in N. Lee and P. Kotler (Eds), Social Marketing: Influencing Behaviours for Good, Fourth Edition, Sage, Thousand Oaks,pp.2-31. 
Steg, L., Vlek, C. and Slotegraaf, G. (2001), Instrumental reasoned and symbolic affective motives for using a motor car, Transportation Research, 4 Part F (3), 151-169.

Train, K. and Winston, C. (2007), Vehicle choice behaviour and the declining market share of US automakers, International Economic Review, 48 (4), 1469-1496.

Urban,G., Weinberg, B. and Hauser, J. (1996), Premarket forecasting of really-new products, Journal of Marketing, 60 (1), 47-60.

Van Liere, K. and Dunlap, R. (1980), The social bases of environmental concern: A review of hypotheses, explanations and empirical evidence, Public Opinion Quarterly, 44 (2), 181-197.

Woelfel, J. (1998), User's Guide: Catpac II Version 2.0, Galileo, New York.

Woelfel, J. and Stoyanoff, N. (1994), Catpac: A neural network for qualitative analysis of text, Australasian Journal of Market Research, 2 (2), 9-18.

Wood, M. (2012), Marketing social marketing, Journal of Social Marketing, 2 (2), 94-102. 
FIGURE 1. SNA OF MANUFACTURERS' PROMOTIONAL MATERIALS

$\underline{\text { Key word clusters }}$

Underlying theme

- Pleasure

- Performance

- Technology (advanced)

Great driving experience

- Fuel (saving)

- Price (reasonable/attracts

Economical subsidy)

- Environment

Preserves the

- Energy environment

FIGURE 2. SNA OF PUBLIC BODIES' WEBSITES

$\underline{\text { Key word clusters }}$

Underlying theme

- Range

- Charging

Range anxiety

- Battery (life)

- Warranties (for batteries)

- Battery toxicity (is low)

Battery issues

- Fuel (efficiency)

- Price (subsidy)

Economical

- Emissions

- Energy

Preserves the

- $\mathrm{CO}_{2}$ environement 


\section{TABLE 1: THE QUESTIONNAIRE}

\section{Section 1: Features of an electric car}

Suppose you were to consider purchasing an electric vehicle (EV). What would be the major considerations that would encourage you to decide to make a purchase? On the next three pages there are 9 statements that present 9 different combinations of features of EVs that might favourably influence you when deciding whether to buy an EV. Please assign a rank to each one of the statements ranging from 1 to 9 to indicate which combinations of features are most or least important to you personally. Rank as number 1 the combination that would be most likely to influence your decision; rank as number 2 the combination of features that you regard as the next most important to you all the way down to the least important combination, which you should rank as number 9 . Each statement contains a slightly different set of features, so you have to decide which sets contain the elements that you find most or least important.

"EVs use the very latest technology and help preserve the environment. EV purchase prices are falling and public recharging points will soon be available everywhere."

"EVs are a pleasure to drive (they are silent, gearless, comfortable and smart) and help preserve the environment. EV prices are falling and EV batteries now last much longer and are becoming cheaper to replace"

"EVs provide good performance (fast acceleration, no gear changes, excellent manoeuvrability, etc.) and give buyers the opportunity to demonstrate that they really do care for the environment. EV purchase prices are falling and the distances that EVs can travel between recharges is going up all the time."

"EVs are a pleasure to drive (they are silent, gearless, comfortable and smooth) and help preserve the environment. EV prices are falling and the distances that EVs can travel between recharges are going up all the time."

"EVs provide good performance (fast acceleration, excellent manoeuvrability, etc.) and help preserve the environment. EV purchase prices are falling and public recharging points will soon be available everywhere"

"EVs use the very latest technology and give buyers the opportunity to demonstrate that they really do care for the environment. EV prices are falling and EV batteries now last much longer and are becoming cheaper to replace."

"EVs provide good performance (fast acceleration, excellent manoeuvrability, etc.), do not require owners to buy any fuel, help preserve the environment, and EV batteries now last much longer and are becoming cheaper to replace"

"EVs are a pleasure to drive (they are silent, gearless, comfortable and smooth) and do not require owners to buy any fuel. EVs give buyers the opportunity to demonstrate that they really do care for the environment and the distances that EVs can travel between recharges are going up all the time."

"EVs use the very latest technology, do not require owners to buy any fuel, help preserve the environment, and the distances they can travel between recharges is going up all the time."

\section{Section 2: About yourself}

I am:

$\square$ Male $\quad \square$ Female 
My age bracket is:
$\square$ under $21 \quad \square 22-30$
$\square 31-40$
$\square 41-50$
$\square 51-60$
$\square 61-70$

$71+$

I have the following number of children living with me:
$\square 0$
$\square 1$
$\square 2$
$\square 3$
$\square$ more than 3

My highest level of educational qualification is:
$\square$ GCSE
$\square$ O' Levels $\square$ GNVQ
$\square$ BTEC National
$\square$ A Levels
$\square$ HND or

Degree $\square$ Professional Qualification $\square$ Postgraduate Qualification

Relative to most other people, I would say that my/our household income is:

$\square$ higher $\square$ lower $\square$ about the same as others

Number of cars in my/our household:
$\square 0$
$\square 1$
$\square 2$
$\square 3$
$\square$ more than 3

Number of drivers in my/our household:
$\square 1$
$\square 2$
$\square 3$
$\square$ more than 3

I/my household have off street parking (in a parking lot, garage or private driveway):

$\square$ YES

$\square \mathrm{NO}$

When I drive my car usage requirements are as follows:

$\square$ all day vehicle use $\quad \square$ short and long distance journeys $\square$ short distance journeys only.

The purpose of most of my car journeys is work related:

$\square$ YES $\square$ NO

My/our household's annual mileage is approximately:

$\square$ less than 3000 miles $\quad \square 3$ to $6 \mathrm{~K} \quad \square 7$ to $10 \mathrm{~K} \quad \square 11-20 \mathrm{~K} \quad \square$ more than $20 \mathrm{~K}$

I am aware that the government offers a $£ 5000$ grant to set against the purchase price of an electric vehicle:

$\square$ YES

$\square \mathrm{NO}$

\section{Section 3: Your attitudes toward the environment and owning an electric car}

Please indicate the strength of your agreement or disagreement with each of the following statements by placing a tick in the appropriate box.

\section{AGREE DISAGREE}

\begin{tabular}{|c|c|c|c|c|c|c|}
\hline & & 1 & 2 & 3 & 4 & 5 \\
\hline (a) & People need to change their lifestyles to protect the environment. & & & & & \\
\hline (b) & Climate change is a serious problem. & & & & & \\
\hline (c) & Climate change is a result of human actions. & & & & & \\
\hline (d) & Environmental problems have been greatly exaggerated. & & & & & \\
\hline (e) & When I drive I use my car frequently for my leisure pursuits. & & & & & \\
\hline (f) & $\begin{array}{l}\text { I try as much as possible to use public transport in order to minimise } \\
\text { my own carbon footprint. }\end{array}$ & & & & & \\
\hline (g) & I have changed my lifestyle to help the environment. & & & & & \\
\hline
\end{tabular}




\begin{tabular}{|l|l|l|l|l|l|}
\hline (h) & I have changed my shopping habits to help the environment. & & & \\
\hline (i) & At home I always try hard to reduce energy consumption. & & & \\
\hline (j) & $\begin{array}{l}\text { I will always choose to buy the most energy efficient home appliances } \\
\text { (refrigerator, washing machine, etc.). }\end{array}$ & & & \\
\hline (k) & $\begin{array}{l}\text { I do everything I can to recycle waste in order to preserve the } \\
\text { environment. }\end{array}$ & & & \\
\hline
\end{tabular}

\section{AGREE DISAGREE}

\begin{tabular}{|c|c|c|c|c|c|c|}
\hline \multirow{2}{*}{\multicolumn{2}{|c|}{$\begin{array}{c}\text { AGREE DISAGREE } \\
\text { Owning an electric vehicle will characterise me as: }\end{array}$}} & \multirow{3}{*}{1} & \multirow[b]{2}{*}{2} & \multirow{2}{*}{3} & \multirow{2}{*}{4} & \multirow[b]{2}{*}{5} \\
\hline & & & & & & \\
\hline$(\mathrm{l})$ & a person who likes technological change & & & & & \\
\hline (m) & a pioneer in the technological sphere & & & & & \\
\hline$(n)$ & a person who is always happy to experience new things & & & & & \\
\hline (0) & a trendsetter for new environmentally friendly technologies. & & & & & \\
\hline
\end{tabular}


TABLE 2. CONJOINT SOLUTIONS

\begin{tabular}{|c|c|c|c|c|}
\hline \multirow[b]{2}{*}{ Variable } & \multicolumn{4}{|l|}{ Part worths } \\
\hline & $\mathrm{C} 1 \quad(\mathrm{~N}=314)$ & $\mathrm{C} 2(\mathrm{~N}=217)$ & C3 $(N=114)$ & $\begin{array}{l}\text { All sample } \\
(\mathrm{N}=645)\end{array}$ \\
\hline Intercept & 4.28 & 3.67 & 6.0 & 7.14 \\
\hline $\begin{array}{ll}\text { Great driving experience: } \\
\text { - } & \text { Pleasure to drive } \\
\text { - } & \text { Good performance } \\
\text { - } & \text { Uses latest technology }\end{array}$ & $\begin{array}{r}2.22 \\
-.11 \\
-2.11\end{array}$ & $\begin{array}{r}-.33 \\
.67 \\
-.34\end{array}$ & $\begin{array}{l}.7 \\
-.1 \\
-.6\end{array}$ & $\begin{array}{r}3.9 \\
-3.4 \\
-.5\end{array}$ \\
\hline $\begin{array}{l}\text { Economical: } \\
\text { - } \quad \text { Prices are falling } \\
\text { - } \quad \text { No need to buy fuel }\end{array}$ & $\begin{array}{r}1.67 \\
-1.67\end{array}$ & $\begin{array}{r}-2.75 \\
2.75\end{array}$ & $\begin{array}{r}.25 \\
-.25\end{array}$ & $\begin{array}{r}-1.17 \\
1.17\end{array}$ \\
\hline $\begin{array}{l}\text { Preserves the environment: } \\
\text { - } \text { Helps preserve the } \\
\text { environment } \\
\text { - Provides opportunity to } \\
\text { demonstrate one's concern } \\
\text { for the environment }\end{array}$ & $\begin{array}{r}-.17 \\
.17\end{array}$ & $\begin{array}{r}-.25 \\
.25\end{array}$ & $\begin{array}{r}2.25 \\
-2.25\end{array}$ & $\begin{array}{r}-1.9 \\
1.9\end{array}$ \\
\hline $\begin{array}{l}\text { Reassurance regarding range } \\
\text { anxiety: } \\
\text { - } \quad \text { Distances between } \\
\text { recharges are increasing } \\
\text { - } \quad \text { Recharge points will soon be } \\
\text { widely available } \\
\text { - } \quad \text { Batteries last longer and are } \\
\text { becoming cheaper to } \\
\text { replace }\end{array}$ & $\begin{array}{r}.78 \\
-.22 \\
-.56\end{array}$ & $\begin{array}{r}.67 \\
-2.33 \\
1.67\end{array}$ & $\begin{array}{r}-1.33 \\
.33 \\
1.0\end{array}$ & $\begin{array}{r}-2.8 \\
2.9 \\
-.11\end{array}$ \\
\hline $\begin{array}{l}\text { R-square (between observed and } \\
\text { estimated preferences) }\end{array}$ & 0.77 & $0 . .75$ & $0 . .81$ & 0.68 \\
\hline Kendall's tau & 0.66 & 0.68 & 0.64 & 0.55 \\
\hline
\end{tabular}


FIGURE 3. AGGREGATE FACTOR IMPORTANCE SCORES

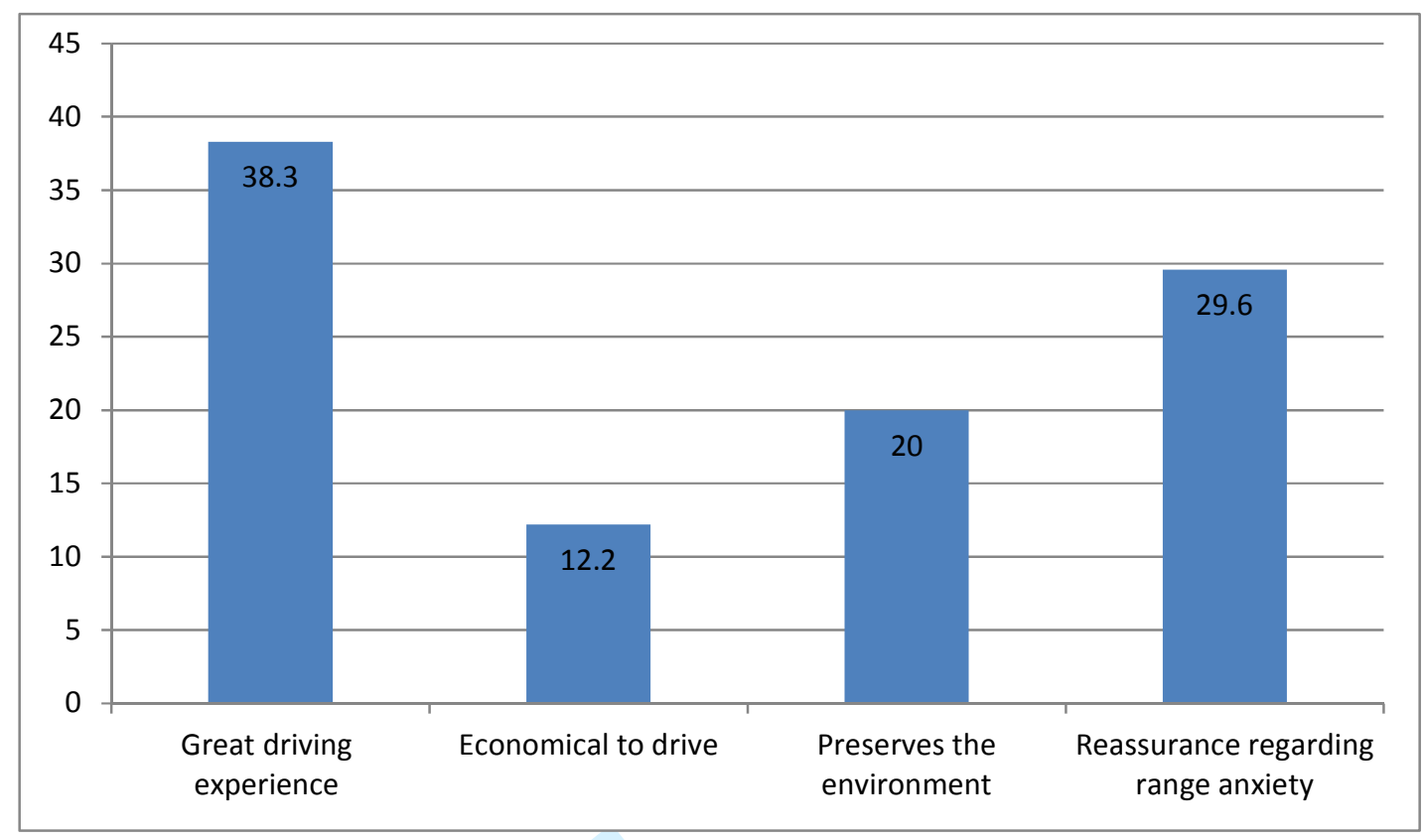

FIGURE 4. FACTOR IMPORTANCE BY CLUSTER

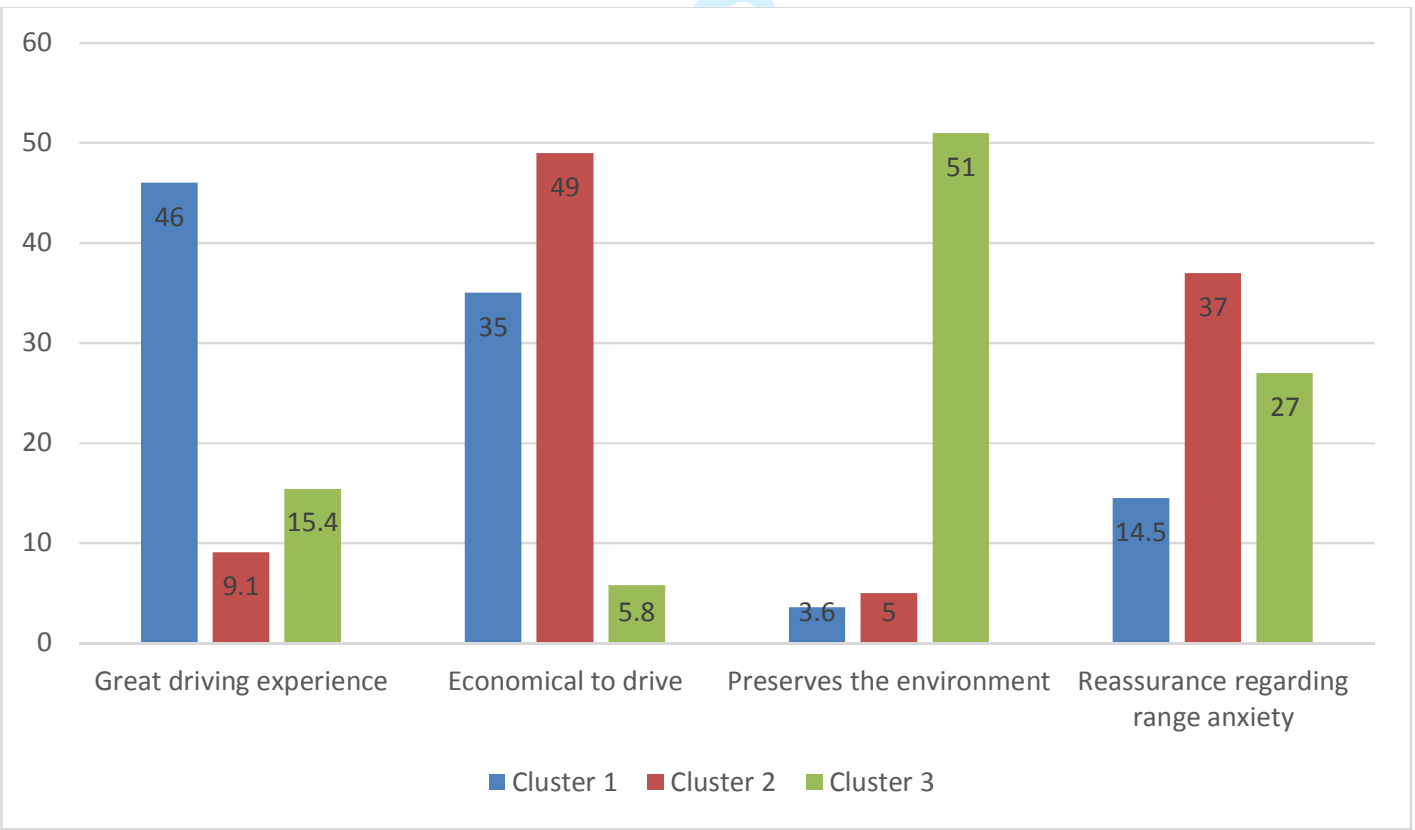


TABLE 3. CHARACTERISTICS OF CLUSTER MEMBERS

\begin{tabular}{|l|l|l|l|}
\cline { 2 - 4 } \multicolumn{1}{c|}{} & C1 & C2 & C3 \\
\hline Gender (\% female) & $59 \%$ & $44 \%$ & $48 \%$ \\
\hline Number of children (average) & 2.8 & 1.5 & 1.9 \\
\hline $\begin{array}{l}\text { Number of cars in household } \\
\text { average) }\end{array}$ & 1.9 & 2.7 & 1.6 \\
\hline Annual mileage (thousands) & 4.4 & 4.9 & 2.7 \\
\hline $\begin{array}{l}\text { Car(s) frequently used for leisure } \\
\text { (mean of 5-point scale) }\end{array}$ & 2.7 & 2.4 & 2.1 \\
\hline $\begin{array}{l}\text { Aware of f5000 government grant } \\
\text { (\%) }\end{array}$ & $13 \%$ & $22 \%$ & $29 \%$ \\
\hline $\begin{array}{l}\text { Concern for the environment } \\
\text { (mean value of composite) }\end{array}$ & 1.9 & 2.2 & 3.6 \\
\hline $\begin{array}{l}\text { Actual environmental behaviour } \\
\text { (mean value of composite) }\end{array}$ & 2.2 & 2.3 & 3.8 \\
\hline $\begin{array}{l}\text { Belief that EV purchase enables } \\
\text { people to display their concern for } \\
\text { the environment (mean value of } \\
\text { composite) }\end{array}$ & 2.4 & 2.3 & 3.3 \\
\hline
\end{tabular}

